Article

\title{
Synergistic Neuroprotective Effect of Schisandra chinensis and Ribes fasciculatum on Neuronal Cell Death and Scopolamine-Induced Cognitive Impairment in Rats
}

\author{
Eunkuk Park ${ }^{1,2,{ }^{\dagger}}$, Min Jeong Ryu ${ }^{3,4,+}$, Nam Ki Kim ${ }^{5}$, Mun Hyoung Bae ${ }^{5}$, Youngha Seo ${ }^{5}$, \\ Jeonghyun Kim ${ }^{1,2}$, Subin Yeo ${ }^{6}$, Memoona Kanwal ${ }^{1,2}$, Chun Whan Choi ${ }^{7}$, \\ Jun Young Heo $3,8,9, *$ (D) and Seon-Yong Jeong $1,2, *$ (D) \\ 1 Department of Medical Genetics, Ajou University School of Medicine, Suwon 16499, Korea \\ 2 Department of Biomedical Sciences, Ajou University Graduate School of Medicine, Suwon 16499, Korea \\ 3 Department of Biochemistry, Chungnam National University School of Medicine, Daejeon 301747, Korea \\ 4 Research Institute for Medical Science Chungnam National University School of Medicine, \\ Daejeon 301747, Korea \\ 5 Rpbio Research Institute, Rpbio Co. Ltd., Suwon 16229, Korea \\ 6 NineB Research Institute, Nine B Co. Ltd., Suwon 16499, Korea \\ 7 Natural Products Research Team, Gyeonggi Business \& Science Accelerator, Suwon 16229, Korea \\ 8 Department of Medical Science, Chungnam National University School of Medicine, Daejeon 301747, Korea \\ 9 Infection Control Convergence Research Center, Chungnam National University School of Medicine, \\ Daejeon 301747, Korea \\ * Correspondence: junyoung3@gmail.com (J.Y.H.); jeongsy@ajou.ac.kr (S.-Y.J.); Tel.: +82-42-580-8222 (J.Y.H.); \\ +82-31-219-4520 (S.-Y.J.); Fax: +82-42-580-8121 (J.Y.H.); +82-31-219-4521 (S.-Y.J.) \\ + These authors contributed equally to this work.
}

Received: 16 August 2019; Accepted: 6 September 2019; Published: 12 September 2019

check for updates

\begin{abstract}
Mild cognitive impairment (MCI) is considered as a transitional stage between aging and Alzheimer's disease. In the present study, we examined the protective effect of Schisandra chinensis (SC) and Ribes fasciculatum (RF) on neuronal cell death in vitro and scopolamine-induced cognitive impairment in Sprague Dawley ${ }^{\circledR}$ rats in vivo. A mixture of SC and RF extracts (SC+RF) significantly protected against hydrogen peroxide-induced PC12 neuronal cell death. The neuroprotective effect of SC+RF on scopolamine-induced memory impairment in rats was evaluated using the passive avoidance test and the Morris water maze test. In the passive avoidance test, SC+RF-treated rats showed an increased latency to escape, compared to the scopolamine-treated rats. Moreover, SC+RF treatment significantly reduced escape latency in water maze test, compared to treatment with scopolamine alone. To verify the long-term memory, we performed probe test of water maze test. As a result, rat treated with $\mathrm{SC}+\mathrm{RF}$ spent more time in the target quadrant. Consistent with enhancement of memory function, the brain derived neurotrophic factor (BDNF) and its downstream molecules (pERK, pATK, and pCREB) are increased in SC+RF treatment in hippocampal area compared with scopolamine treated group. These results suggest that a mixture of SC and RF extracts may be a good therapeutic candidate for preventing mild cognitive impairment.
\end{abstract}

Keywords: herbal medicine; Schisandra chinensis; Ribes fasciculatum; neuroprotection; neuronal cell death; ccopolamine-induced cognitive impairment 


\section{Introduction}

Mild cognitive impairment (MCI) is known as early dementia and isolated memory impairment, which commonly affects elderly people [1]. Delays or prevention of MCI are important because people with MCI are at high-risk for developing Alzheimer's or other dementia [2,3]. However, United States Food and Drug Administration (FDA)-approved drugs inhibiting the cholinesterase or $\mathrm{N}$-methyl-D-aspartate receptor, such as Aricept (donepezil), Exelon (rivastigmine), and Namenda (memantine), only mitigate the symptoms of Alzheimer's disease [4-6]. Moreover, some of these drugs should not be used in the long-term due to how they affect heart rate and the nervous system, causing side effects such as arrhythmia [7]. To overcome the drawback of modern therapeutics, natural plants have emerged as alternative medicine in prevention therapy for transitional state of disease, which have low-risk of developing side effects [8].

Schisandra chinensis (SC), a deciduous woody vine, has been used as a traditional herbal medicine for the treatment of cancer and diabetes via immunomodulatory and antioxidant activities [9]. Bioactive compounds such as schisandrin $B$, a dibenzocyclooctadiene derivative isolated from SC, have been studied for their neuroprotective effects in scopolamine-induced amnesia, amyloid beta (A $\beta$ ) peptide-induced neurotoxicity, and cisplatin-induced neurotoxicity [10,11]. In addition, schisanhenol isolated from SC has been shown to improve learning and memory in scopolamine-treated mice [12]. Although protective effects of various extracts of SC were reported on neuronal injury and memory impairment, the underlying mechanism of it still did not defined with the brain derived neurotrophic factor (BDNF) signaling, and revealed that correlation with antioxidant enzyme activation $[13,14]$, NF-kB inhibition [15], and recovered Ach levels [10,16].

Here, we found out protective role of neuronal cell death by Ribes fasciculatum (RF), a perennial woody deciduous member of the Ribes genus in the family Grossulariaceae, is distributed widely in Korea and China. Previous studies have reported that RF has been shown to increase the lifespan and stress resistance of Caenorhabditis elegans through SIR-2.1-mediated DAF-16 activation depending on the insulin/insulin growth factor signaling pathway [17]. Moreover, RF inhibited the transcription of nuclear factor of activated T cells (NFAT) [18] and the secretion of inflammatory cytokines in a mouse model of atopic dermatitis [19]. Since nuclear factors of activated T cells (NFATc4) have been reported to be required for BDNF-dependent survival of adult-born neurons and spatial memory formation in the hippocampus, we focused on the possibility that combination of SC and RF could enhance protection against cognitive impairment through the BDNF signaling pathway.

Ultimately, in the present study, we aimed to investigate whether SC and RF extracts have a protective effect on reactive oxygen species (ROS)-induced cytotoxicity in pheochromocytoma PC12 cells and scopolamine-induced cognitive impairment in rats.

\section{Results}

\subsection{Verification of Increasing Hydrogen Peroxide $\left(\mathrm{H}_{2} \mathrm{O}_{2}\right)$ Concentrations on Neuronal Cell Death}

Neuronal apoptosis in neurodegenerative diseases is associated with ROS production. Therefore, we tested the effect of $\mathrm{H}_{2} \mathrm{O}_{2}$ on neuronal cell death in the PC12 neuronal cell line. Cells were treated with various concentrations of $\mathrm{H}_{2} \mathrm{O}_{2}(0-100 \mu \mathrm{M})$ for $1 \mathrm{~h}$ and neuronal apoptosis was measured by the WST assay. Neuronal cell death occurred in a concentration-dependent manner. A $1 \mathrm{~h}$ incubation with $50 \mu \mathrm{M} \mathrm{H}_{2} \mathrm{O}_{2}$-induced approximately $40 \%$ of the cells to undergo apoptosis; finally, we selected $50 \mu \mathrm{M}$ $\mathrm{H}_{2} \mathrm{O}_{2}$ for the subsequent experiments (Figure 1). 


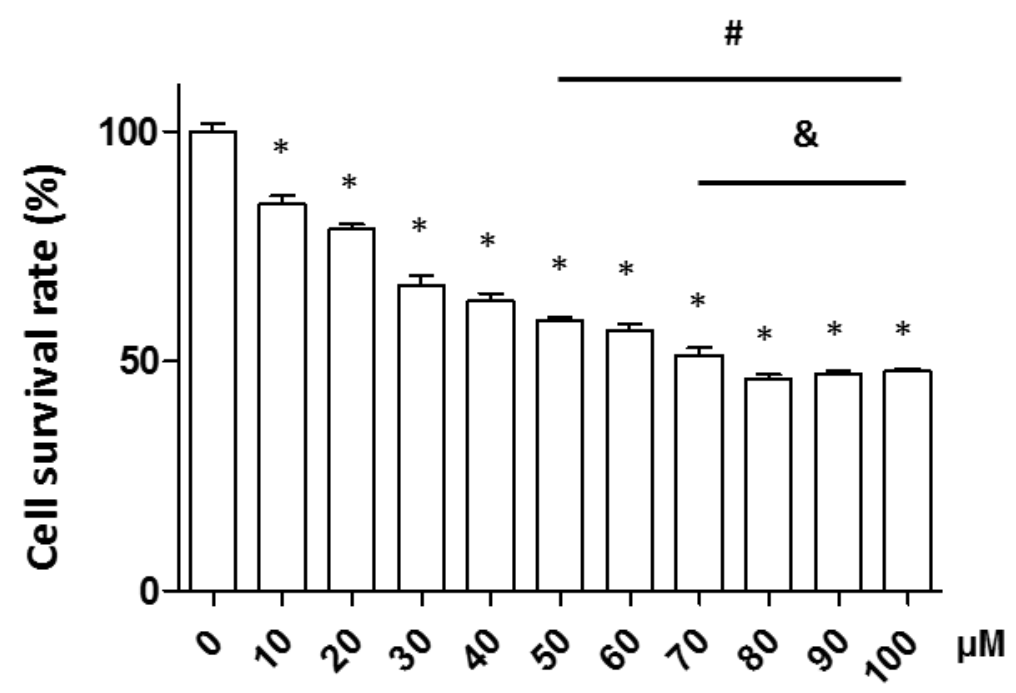

Figure 1. Neuronal cell survival rate in various concentrations of $\mathrm{H}_{2} \mathrm{O}_{2}$. Cells were treated with various concentrations of $\mathrm{H}_{2} \mathrm{O}_{2}(0,10,20,30,40,50,60,70,80,90$, or $100 \mu \mathrm{M})$ and cell viability was measured by the tetrazolium salt (WST) assay. The data shown are means \pm standard error of the mean (SEM). *: $p<0.05$ vs. $0 \mu \mathrm{M}, \#: p<0.05$ vs. $30 \mu \mathrm{M}$, and $\&: p<0.05$ vs. $40 \mu \mathrm{M}$.

\subsection{Protective Effect of SC and RF on $\mathrm{H}_{2} \mathrm{O}_{2}$-Induced Neuronal Cell Death}

To identify the effectiveness of herbal medicine against nerve cell loss, we screened 42 herbal medicines with PC12 cells. Further, we selected SC and RF extracts due to have higher potency than other candidates (Supplementary Table S1). To investigate the protective effect of ethanol extracts of SC and RF against $\mathrm{H}_{2} \mathrm{O}_{2}$-induced neuronal cell death, we incubated PC12 neuronal cells for $24 \mathrm{~h}$ with either of three different concentrations of SC and RF $(2,10$, or $50 \mu \mathrm{g} / \mathrm{mL})$ extracted at various ethanol percentages $(0 \%, 30 \%, 70 \%$, or $100 \%)$. Cells were pre-incubated with SC and RF for $23 \mathrm{~h}$ and then co-incubated with hydrogen peroxide for $1 \mathrm{~h}$. In previous reports, SC extracted with 50\% ethanol was most effective when performing various chemical properties such as total phenolic compounds (TPC) and antioxidant activity (2,2-diphenyl-1-picrylhydrazyl (DPPH) and 2,2'-azino-bis 3-ethylbenzothiazoline-6-sulphonic acid (ABTS) analysis) [20]. Consistent with the previous report, cells treated with $30 \%$ ethanol extracts of SC and RF had the highest survival rate, compared to those treated with $0 \%, 70 \%$, or $100 \%$ ethanol extracts. The greatest neuroprotective effect was observed at a concentration of $50 \mu \mathrm{g} / \mathrm{mL}$ for both 30\% ethanol extracts of SC and RF (Supplementary Figure S1 and Figure 2). However, SC and RF did not have cytotoxic effects (Supplementary Figure S2). These results suggested that the $30 \%$ ethanol extracts of $\mathrm{SC}$ and RF protected against $\mathrm{H}_{2} \mathrm{O}_{2}$-induced reduction of cell viability without exerting a cytotoxic effect.

To investigate a synergistic effect of SC and RF extracts against $\mathrm{H}_{2} \mathrm{O}_{2}$-induced cell death, we determined the cell survival rate of PC12 neuronal cells treated with various ratios of SC and RF (6:4, 7:3, or 8:2). All SC+RF combinations inhibited $\mathrm{H}_{2} \mathrm{O}_{2}$-induced cell death. The greatest protective effect against $\mathrm{H}_{2} \mathrm{O}_{2}$-induced cell death occurred when a 7:3 ratio of $50 \mu \mathrm{g} / \mathrm{mL} \mathrm{SC}+\mathrm{RF}$ was administrated (Figure 3A). The mixture did not have any cytotoxic effects (Supplementary Figure S3). Interestingly, the mixture of $50 \mu \mathrm{g} / \mathrm{mL} \mathrm{SC}+\mathrm{RF}$ exerted a greater protective effect than the single extracts of SC or RF at $50 \mu \mathrm{g} / \mathrm{mL}$ (Figure 3B). These results suggested that 30\% ethanol extracts of $\mathrm{SC}$ and RF at a 7:3 ratio exerted a synergistic protective effect against $\mathrm{H}_{2} \mathrm{O}_{2}$-induced cell death in PC12 neuronal cells. Next, we analyzed the main constituent of single extract of SC and RF and combination of SC and RF (7:3), using a high-performance liquid chromatography-electrospray ionization-tandem mass spectrometry (HPLC-ESI-MS) system. Ion current chromatogram of the SC and RF and combination of SC and RF (7:3) showed the most abundant constituents identified in SC (shizandrin) and in RF (4-hydrobenzoic acid) (Supplementary Figure S4). Although we did not perform HPLC with the content of the extracted 
compounds under all extraction conditions, pharmacological studies have been conducted on active extracts that have a protective effect on hydrogen peroxide-induced neuronal cell death. Taken together, we assert that shizandrin and 4-hydrobenzoic acid are major constituents with 30\% ethanol extract that have a protective effect on hydrogen peroxide-induced neuronal cell death.

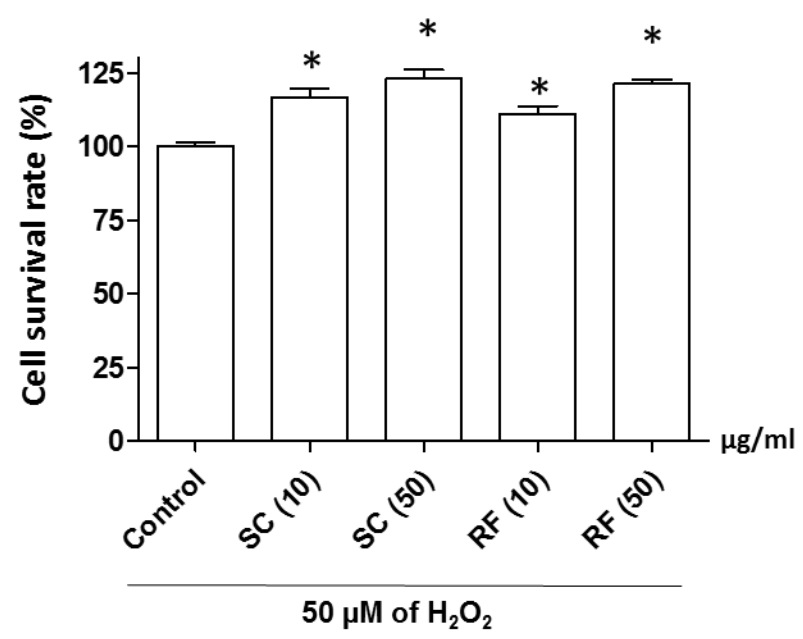

Figure 2. Effect of Schisandra chinensis (SC) and Ribes fasciculatum (RF) extracts on cell survival rate. SC and RF were extracted with 30\% ethanol and PC12 neuronal cells were treated with SC and RF extracts at 10 or $50 \mu \mathrm{g} / \mathrm{mL}$. The protective effect of SC and RF extracts were measured by the WST assay. Control is a treatment of $50 \mu \mathrm{M}$ of $\mathrm{H}_{2} \mathrm{O}_{2}$. ${ }^{*}: p<0.05$ vs. control.
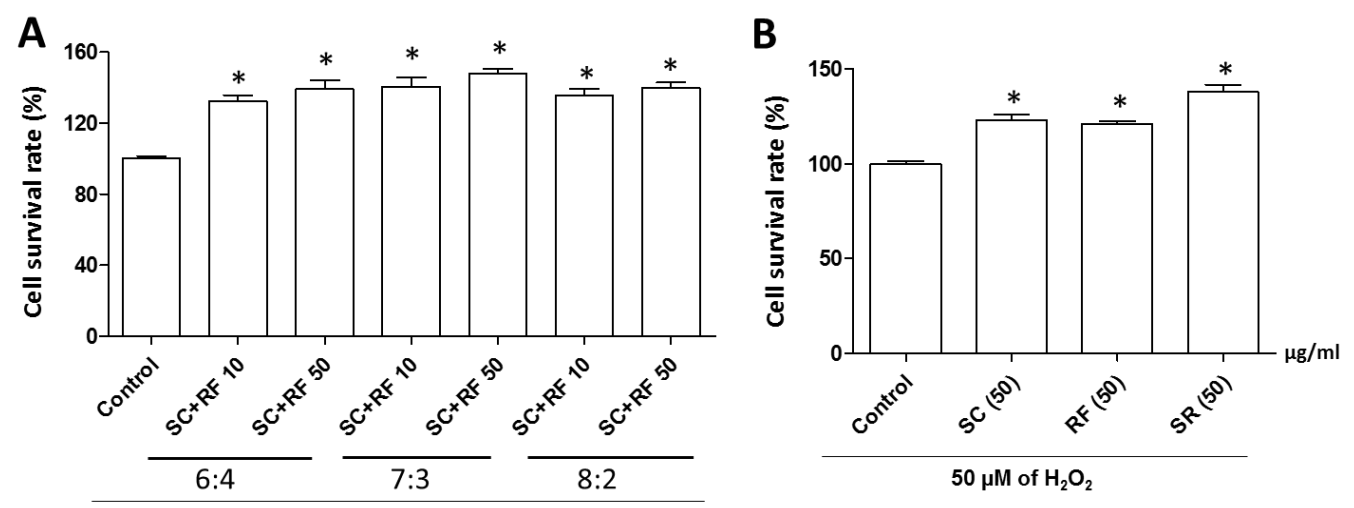

Figure 3. Effect of single or combined Schisandra chinensis (SC) and Ribes fasciculatum (RF) extracts on neuronal cell survival rate. PC12 neuronal cells were treated with different ratios $(6: 4,7: 3$, or 8:2) of SC and RF at concentrations of 10 or $50 \mu \mathrm{g} / \mathrm{mL}$ (A). The effect of single or combined SC and RF extracts (SR) on cell survival rate was compared (B). Control is a treatment of $50 \mu \mathrm{M}$ of $\mathrm{H}_{2} \mathrm{O}_{2}$. ${ }^{*}$ : $p<0.05$ vs. control.

\subsection{A Mixture of SC and RF Extracts Prevent Scopolamine-Induced Cognitive Impairment in Rats}

Based on the in vitro study, we further investigated the neuroprotective effect of an extract mixture of SC and RF (SR) on scopolamine-induced memory impairment in vivo. Scopolamine is a drug that can induce cognitive deficits in healthy humans and animals [21]. The neuroprotective effect of SC and RF on scopolamine-induced memory impairment in rats was evaluated by the passive avoidance test and Morris water maze test. The rats used were seven week old Sprague Dawley ${ }^{\circledR}$ males and were orally administered a mixture of $\mathrm{SC}+\mathrm{RF}(75,150$, or $300 \mathrm{mg} / \mathrm{kg} /$ day $)$ for 23 days before a scopolamine injection ( $1 \mathrm{mg} / \mathrm{kg}$, injected intraperitoneally). The passive avoidance test and Morris water maze test were performed $30 \mathrm{~min}$ after scopolamine administration. Phosphatidylserine (PS), a phospholipid that reduces the risk of dementia and cognitive dysfunction in the elderly, as announced by the FDA, was used as a positive control. As expected, PS treatment restored scopolamine-induced spatial 
learning and memory impairment. Comparing with PS treatment, in passive avoidance test, rats treated with SC+RF showed increased latency time (Figure 4A), without changes in body weight (Supplementary Figure S5A). This result suggests that SC and RF improve memory based on fear motivation. In the Morris water maze test, we did not find significant differences between rats treated with scopolamine and SC+RF (SR) and rats treated with scopolamine alone until day four (Figure 4B and Supplementary Figure S6). However, at day five, rats treated with scopolamine and SR (75 or $150 \mathrm{mg} / \mathrm{kg} /$ day) showed significantly reduced escape latency value, compared to scopolamine-treated rats (Figure 4B,C), without changes in body weight (Supplementary Figure S5B). On the water maze test, learning and memory were assessed on a probe trial. Rats treated with $\mathrm{SC}+\mathrm{RF}$ spent more time in the target quadrant (Figure 4D). This result indicates that treatment of SC and RF restored scopolamine-induced spatial learning and memory impairment.

A

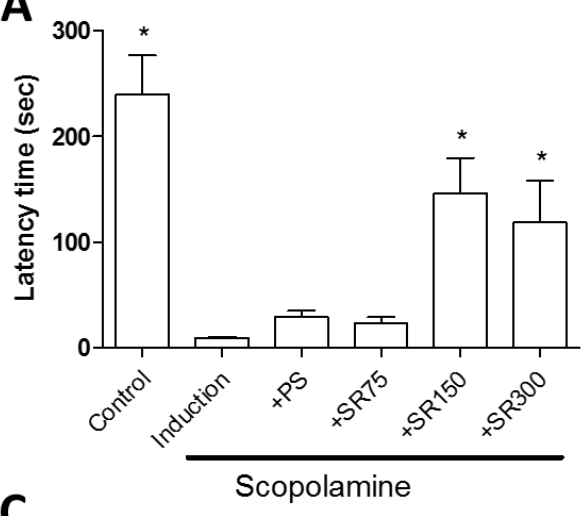

C

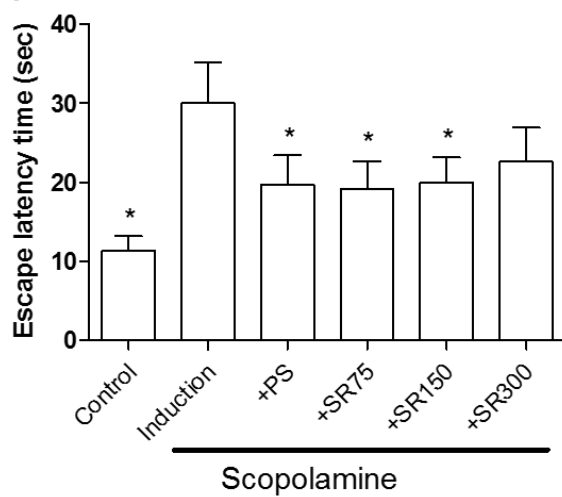

B

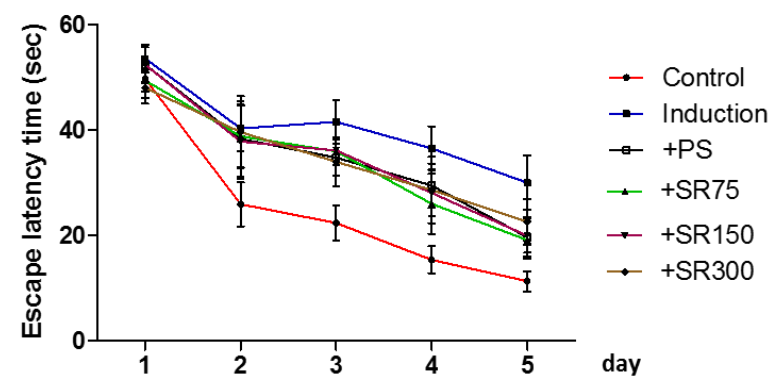

D

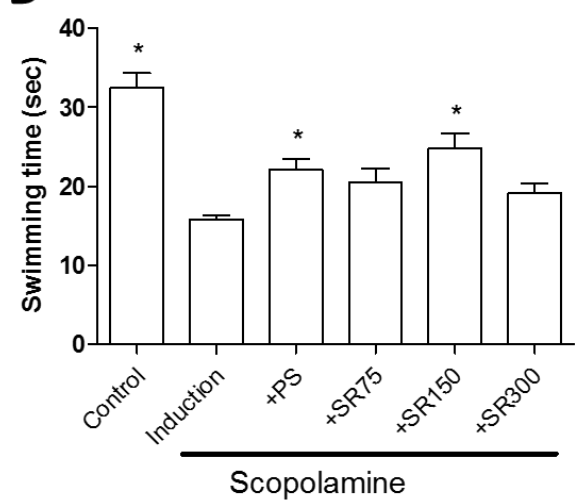

Figure 4. Effect of SC and RF extracts on scopolamine-induced cognitive impairment in scopolamine-treated rats. Rats were treated orally with SC+RF (SR) $(75,150$, or $300 \mathrm{mg} / \mathrm{kg} /$ day) for 23 days and memory impairment was measured by the passive avoidance test and Morris water test. Fear motivation in the passive avoidance test was evaluated by latency time in scopolamine-treated rats (A). Escape latency time was measured daily for five days (B) and a significantly reduced escape latency time in SR treated-rats ( 75 or $150 \mathrm{mg} / \mathrm{kg} /$ day) was observed at day five (C). On the last day of the Morris water maze, swimming time in the target quadrant was measured (D). ${ }^{*}: p<0.05$ vs. Induction. Abbreviation: PS, phosphatidylserine.

\subsection{A Mixture of SC and RF Extracts Exerts Neuroprotection via BDNF Signaling in Hippocampus}

BDNF have function in differentiation and survival of neurons of the CNS and in the enhancement of synaptogenesis and synaptic plasticity in the adult CNS [22,23]. To verify the change of BDNF using $\mathrm{SC}$ and RF extracts, we performed the western blot analysis. Consistent with behavioral test, BDNF was inhibited by scopolamine, and recovered by treatment with PS, but increased further by administration of SC and RF (Figure 5A,B). To identify the involvement of BDNF signaling pathway by SC and RF in scopolamine treated rat model, we measured the phosphorylation of extracellular signal-regulated 
kinase (ERK), cAMP response element binding (CREB) protein, and AKT/protein kinase B (PKB). Surprisingly, treatment of PS did not restore scopolamine-induced reduction of phosphorylated ERK, CREB and AKT (Figure 5A,C-E).

Taken together, these results indicate that a mixture of SC and RF extracts prevents scopolamine-induced long-term spatial learning and memory impairment, through activation of BDNF-induced signaling cascade.
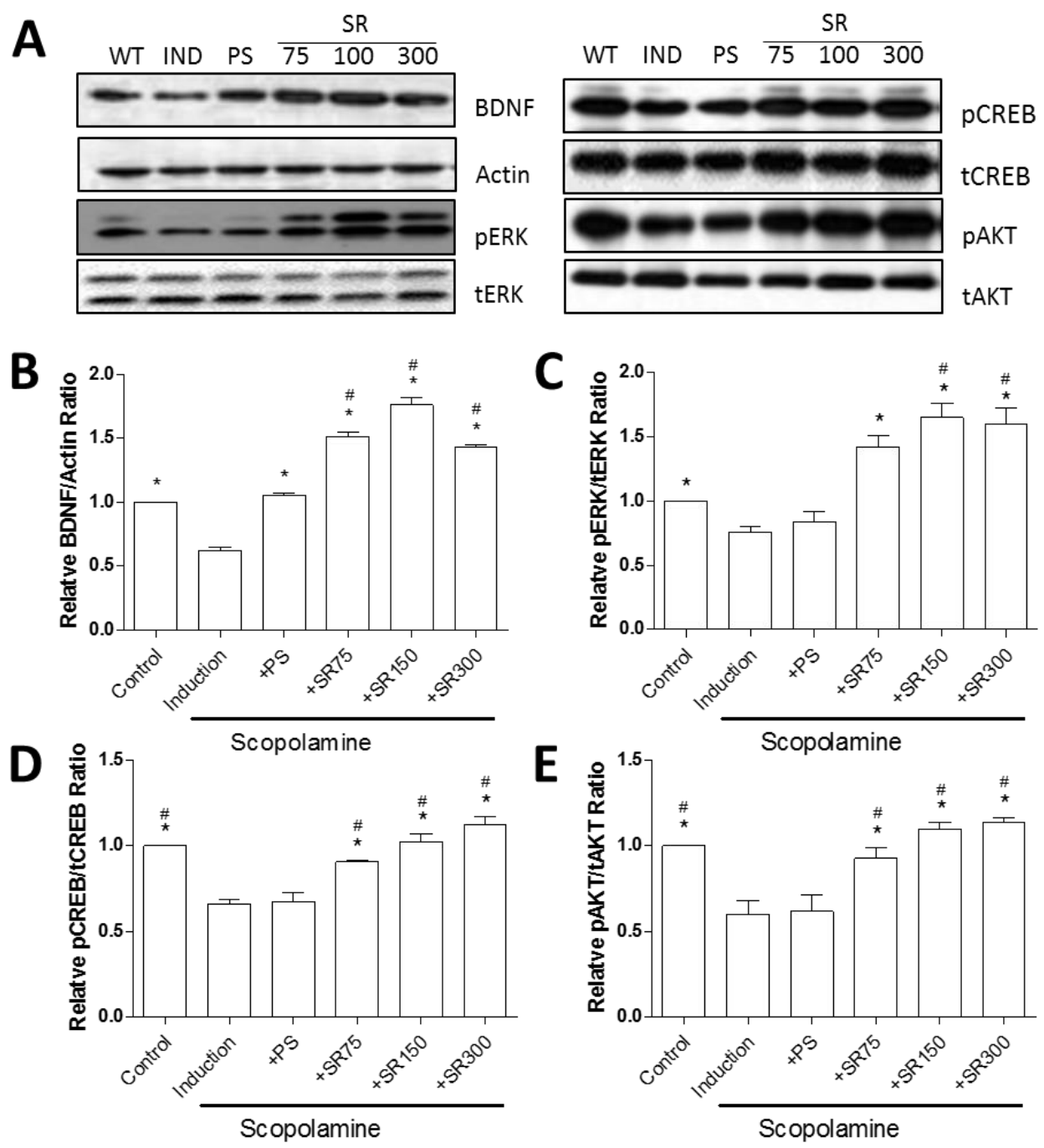

Figure 5. Involvement on brain derived neurotrophic factor (BDNF) signaling pathway for treatment of SC and RF extracts. Rats were treated orally with SC+RF (SR) $(75,150$, or $300 \mathrm{mg} / \mathrm{kg} / \mathrm{day})$ for 28 days. Hippocampus was extract $30 \mathrm{~min}$ after an intraperitoneal injection of $1 \mathrm{mg} / \mathrm{kg}$ scopolamine. Western blot analysis with specific antibodies and Actin was used for loading control (A). Relative band ratio was calculated with image J (B-E). * $p<0.05$ vs. Scopolamine induction. \#: $p<0.05$ vs. PS. Abbreviation: PS, phosphatidylserine. SCO, Scopolamine.

\section{Discussion}

Alzheimer's disease is an age-related neurodegenerative disorder characterized clinically by the progressive degeneration of memory and cognitive functions by hippocampal neuronal loss [24,25]. In this study, we investigated the neuroprotective effect of SC and RF on oxidative stress induced by $\mathrm{H}_{2} \mathrm{O}_{2}$ in a neuronal cell line in vitro and on scopolamine-induced memory impairment in rats in vivo.

Oxidative stress and inflammation have been implicated in neurodegeneration, including cognitive impairment [26]. SC has been extensively studied for its immunomodulatory, antioxidant, anticancer, 
and cognition/memory-improving activities $[10,11,27,28]$. In addition, SC has been shown to protect the liver, kidney, and nervous system in cyclophosphamide-treated rats [27]. Studies have reported that $S C$ and its active ingredients protect against neurological diseases $[29,30]$ and improve cognitive impairment in $A \beta$ 1-42-induced neurodegeneration in mice [31]. In turn, RF inhibits the NFAT transcription factor [17] and exerts a pharmacological action in allergic inflammatory diseases through the reduction of nuclear factor-kappa B activation in lipopolysaccharide-stimulated macrophages [32]. Recently, RF has been shown to have anti-aging properties via increased longevity and stress resistance in C. elegans [19]. In the present study, both SC and RF prevented neuronal cell death were induced using $\mathrm{H}_{2} \mathrm{O}_{2}$. Among a range of ethanol extracts, the $30 \%$ ethanol extracts of SC and RF were the most effective in reducing neuronal cell death. Furthermore, a synergistic effect of $30 \%$ ethanol extracts of $\mathrm{SC}+\mathrm{RF}$ was observed at a 7:3 combination ratio. Compared to the single extracts of SC or RF, a mixture of $\mathrm{SC}+\mathrm{RF}$ showed greater protection against neuronal cell death. These results suggest that a combination of SC and RF prevented oxidative stress-induced neuronal cell death without undesirable adverse effects.

Scopolamine has been used to generate a model of amnesia in mice that leads to increased oxidative stress with impairment of memory and cognitive functions [33]. The amnesic effect of scopolamine has also been demonstrated in rodents [34]. Based on the results of our in vitro experiment, we investigated the neuroprotective effect of SC and RF on scopolamine-induced memory impairment in rats. Cognitive impairment was evaluated by the Morris water maze and the passive avoidance test. The Morris water maze has been extensively used in the behavioral neurosciences to assess spatial learning and memory [35]. Since rats in each group entered the dark compartment immediately after being placed in the illuminated compartment, the latency time during the training period was very short. The passive avoidance test is a fear-aggravated test used to evaluate learning and memory. We found that scopolamine-treated rats showed increased escape latency and decreased time in the target quadrant, compared to the control group. In contrast, treatment with SC+RF increased escape latency and time in the target quadrant in scopolamine-treated rats. Similarly, scopolamine disrupted passive avoidance memory retrieval, but the latency time was improved by treatment with SC+RF. These results suggest that SC and RF may prevent scopolamine-induced memory impairment in rats.

Regarding the enhancement of cognitive and memory function, we assure that the BDNF signaling are associated with neuroprotective effect of SC and RF treatment. BDNF is a predominant neurotrophic factor involved in AD that activates Tropomyosin receptor kinase B (TrkB) receptors and phosphorylates signaling proteins to induce neural differentiation and survival [36]. Recently, numerous reports suggested that BDNF can affect synaptogenesis and synaptic plasticity in adult central nervous system (CNS) [22,37-39]. Of note, SC could modulate BDNF, TrkB/ cAMP response element binding protein (CREB)/ extracellular-signal-regulated kinase (ERK), and Phosphoinositide 3-kinase (PI3K)/AKT/glycogen synthase kinase 3 beta(GSK-3 $\beta$ ) in the hippocampus and attenuate the depression-like emotional status and associated cognitive deficits in chronic unpredictable mild stress mice or corticosterone-induced mice [40,41]. In our scopolamine-induced cognitive impairment model, SC and RF also ameliorated with activation of BDNF and its downstream signaling pathway (CREB/ERK/AKT). By activation of the BDNF, neurotrophic signaling stimulated mainly through the activation of CREB/ERK/AKT pathway which ultimately improved neuronal cell survival, differentiation, growth, synaptic plasticity, and long-term memory. Thus, activation of BDNF-induced signaling cascade by treatment of SC and RF mediated the neuroprotective effects against scopolamine-induced animal model. Underlying mechanism of combined therapy, specifically RF treatment, for protective effects and synaptic plasticity in scopolamine induced rats is needed further investigation. 


\section{Materials and Methods}

\subsection{Preparation of SC and RF Extracts}

A total of 42 plant extracts were originally provided from the Korea Plant Extract Bank at Korea Research Institute of Bioscience and Biotechnology (KRIBB) (Ochang, Chungbuk, Korea) [42]. The ethanol extracts were prepared based on a previous report [43]. Briefly, after botanical authentication, the dried plant material was turned into powder using a grinding mill. Next, $100 \mathrm{~g}$ of plant powder was extracted in $1000 \mathrm{~mL}$ of $0 \%, 30 \%, 50 \%, 70 \%$, and 100\% aqueous ethanol solution (v/v) in an occasional shaker at room temperature for $72 \mathrm{~h}$. The extract was then filtered with Whatman No. 2 filter paper (GE Healthcare Life Sciences, Logan, UT, USA) to remove debris, and the filtrate was collected and concentrated in a rotating evaporator at $40-50{ }^{\circ} \mathrm{C}$ and lyophilized under reduced pressure. The dried extract was stored in amber flasks at $4{ }^{\circ} \mathrm{C}$, re-suspended with distilled water, and filtered through a $0.22-\mu \mathrm{m}$ membrane filter (Sartorius, Gottingen, Germany) before the experiments.

\subsection{Cell Culture and Cytotoxicity Assay}

The rat PC12 cell line was purchased from the Korean Cell Line Bank (Seoul, Korea) and cultured at $37^{\circ} \mathrm{C}$ and $5 \% \mathrm{CO}_{2}$ with Dulbecco's Modified Eagle Medium (Thermo Fisher Scientific, Inc., Waltham, MA, USA) supplemented with 10\% fetal bovine serum (GE Healthcare Life Sciences), $100 \mathrm{U} / \mathrm{mL}$ penicillin, and $100 \mathrm{mg} / \mathrm{mL}$ streptomycin. The PC12 cells $\left(1 \times 10^{4}\right.$ cells per well $)$ were plated in 96-well plates. To test the effect of $\mathrm{H}_{2} \mathrm{O}_{2}$ on neuronal cell death in the PC12 neuronal cell line, cells were treated with various concentrations of $\mathrm{H}_{2} \mathrm{O}_{2}$ (Sigma Aldrich, Inc., St. Louis, MO, USA) (0-100 $\mu \mathrm{M}$ ) for $1 \mathrm{~h}$ and WST assay was performed. To test the protective effect of $\mathrm{SC}$ and $\mathrm{RF}$ in $\mathrm{H}_{2} \mathrm{O}_{2}$ induced neuronal cell death, the cells were pre-incubated with different concentrations of SC and RF $(2,10$, or $50 \mu \mathrm{g} / \mathrm{mL})$ for $23 \mathrm{~h}$ and then added with $50 \mu \mathrm{M}$ of $\mathrm{H}_{2} \mathrm{O}_{2}$ for $1 \mathrm{~h}$. We used the EZ-Cytox Cell Viability Assay Kit (Daeil, Korea) to assess cell viability. After serial treatment of SC, RF, and hydrogen peroxide, WST (20 $\mu \mathrm{L} ; 5 \mathrm{mg} / \mathrm{mL}$ in phosphate-buffered solution) was added to each well and the cells were incubated for another $4 \mathrm{~h}$. WST is reduced by dehydrogenase in cells to form an orange-colored formazan. The amount of formazan and the number of living cells are in direct proportion. Absorbance was measured at wavelength of $450 \mathrm{~nm}$ and $655 \mathrm{~nm}$ (for reference) using a microplate reader (Bio-Rad, Hercules, CA, USA)

\subsection{In Vivo Experiments in Scopolamine-Treated Rats}

In this study, seven-week-old male Sprague Dawley ${ }^{\circledR}$ rats were used. Animals were allocated in groups and were allowed to accommodate for one week in the animal house. Rats were provided with a standard chow diet and were given water ad libitum. During the experimental period, the animals were kept at a temperature of $22 \pm 3{ }^{\circ} \mathrm{C}$, a 12-h light/dark cycle, and a relative humidity varied between $40 \%$ and $60 \%$. Animals were treated with either of six different conditions: (1) vehicle; (2) scopolamine (1 mg/kg) (Sigma Aldrich, Inc.); (3) scopolamine with $50 \mathrm{mg} / \mathrm{kg} /$ day of PS as a positive control; (4) scopolamine with $75 \mathrm{mg} / \mathrm{kg} /$ day of SC+RF (SR (75)); (5) scopolamine with $150 \mathrm{mg} / \mathrm{kg} / \mathrm{day}$ of SC+RF [SR (150)]; and (6) scopolamine with $300 \mathrm{mg} / \mathrm{kg} /$ day of SC+RF (SR (300)). Rats were orally administrated SC+RF for 28 days. The animal research protocol was approved by the Animal Care and Use Committee of the Ajou University School of Medicine, and all experiments were conducted in accordance with the institutional guidelines established by the Committee.

\subsection{Behavioral Studies}

\subsubsection{Passive Avoidance Test}

A passive avoidance test was conducted as described previously [44] with mild modification. The device used for the passive avoidance test consisted of an illuminated and a dark room separated by an acrylic plate featuring small passages (total volume, $490 \times 250 \times 300 \mathrm{~mm}^{3}$; Daejong Inc., Korea). 
After 23 days of treatment with $\mathrm{SC}+\mathrm{RF}$, the learning phase was performed for five days. The rats were placed in the illuminated section without light and adaptation was allowed for $60 \mathrm{~s}$. Then, when the light was turned on and the guillotine door was opened, the rat entered the dark compartment through the open passage. After entering the dark compartment, a foot shock ( $0.5 \mathrm{~mA}$ for $3 \mathrm{~s})$ was delivered to the floor grid in the dark compartment as the guillotine door closed. After $24 \mathrm{~h}$ of the training trial, the acquisition test was carried out $30 \mathrm{~min}$ after an intraperitoneal injection of $1 \mathrm{mg} / \mathrm{kg}$ scopolamine. The time spent in the illuminated compartment was defined as the latency period. The test was terminated if the rats did not enter the dark room for $300 \mathrm{~s}$.

\subsubsection{Morris Water Maze}

The Morris water maze test was carried out as described previously [45] with slight modification. The water maze consisted of a large circle pool and divided into four equal quadrants. A white plastic platform was submerged in one of the quadrants of the pool, $1 \mathrm{~cm}$ below the surface of the water. A large circle pool was filled to a depth of $30 \mathrm{~cm}$ with opaque water containing kids' paint (Black Kidsmomart, Korea) so as to hide the plastic platform. The rats were allowed to stay on the white plastic platform for $10 \mathrm{~s}$ and the experiment was started four times in different directions. After 23 days of treatment with $\mathrm{SC}+\mathrm{RF}$, the Morris water maze test was performed for five days. A SMART video tracking system (Smart 3.0; Panlab Harvard Apparatus, Barcelona, Spain) was used to monitor and analyze all swimming activity and to record escape latency, swim distance, and speed. The test was carried out $30 \mathrm{~min}$ after an intraperitoneal injection of $1 \mathrm{mg} / \mathrm{kg}$ scopolamine (Sigma Aldrich, Inc.). The time taken to find the hidden platform was recorded as the escape latency.

\subsection{Protein Isolation and Western Blotting}

Proteins of hippocampus tissues were extracted using RIPA buffer ( $1 \%$ Nonidet P- $40,0.1 \%$ SDS, $150 \mathrm{mM} \mathrm{NaCl}, 50 \mathrm{mM}$ Tris- $\mathrm{HCl} \mathrm{pH} 7.5$, and $0.5 \%$ deoxycholate) with $10 \%$ of phosphatase inhibitor and protease inhibitor (Roche, Basel, Switzerland). Proteins were loaded on SDS-PAGE gel and run by electrophoresis, and then transferred to polyvinylidene fluoride (PVDF) membrane. Membrane blocked by $5 \%$ skim milk for $1 \mathrm{~h}$, and incubated with primary antibody including anti-pERK (9102, Cell signaling Technology, Beverly, MA, USA), anti-tERK (9101s, Cell signaling Technology), anti-BDNF (ab108319, Cambridge, MA, USA), anti-pCREB (9198, Cell signaling Technology), anti-tCREB (9197, Cell signaling Technology), anti-pAKT(9271, Cell signaling Technology), anti-tAKT (9272s, Cell signaling Technology), and anti-Actin (sc-1616, Santa Cruz, CA, USA) antibodies at $4{ }^{\circ} \mathrm{C}$ for overnight. Anti-IgG horseradish peroxidase antibody (Pierce Biotechnology, MA, USA) correspond with the host of primary antibody was used as secondary antibody. Proteins band was detected by ECL system (Thermo Scientific, Inc.). The quantification of band intensity was normalized with actin using Image J program (version 1.52c; National Institutes of Health, Bethesda, MD, USA).

\subsection{Statistical Analysis}

A statistical software package (SPSS 11.0 for Windows, SPSS Inc., Chicago, IL, USA) was used to perform the statistical tests. The statistical significance of the differences between groups was assessed by the Student's $t$-test. Comparisons of multiple groups were done with a one-way analysis of variance, followed by Tukey's honest significant difference post-hoc test for correction of multiple comparisons. A probability value $(p)$ less than 0.05 was considered statistically significant. The results are expressed as mean \pm standard error of the mean and all experiments were repeated at least three times.

\section{Conclusions}

Our study shows that SC and RF protected neuronal cells against $\mathrm{H}_{2} \mathrm{O}_{2}$-induced cell death. Moreover, SC and RF prevented cognitive impairment via BDNF signaling pathway in a scopolamine-induced rat model. Our findings indicate the potential of SC and RF for use in the prevention and treatment of cognitive impairment in humans with Alzheimer's disease. 
Supplementary Materials: Supplementary materials can be found at http://www.mdpi.com/1422-0067/20/18/ $4517 / \mathrm{s} 1$.

Author Contributions: S.-Y.J., E.P., and J.Y.H. designed the research; E.P., M.J.R., M.H.B., Y.S., J.K., and S.Y. performed the research and analyzed the data; C.W.C., M.J.R., N.K.K., M.K., and M.H.B. interpreted the data; E.P., M.J.R., C.W.C., and Y.S. wrote the paper; and S.-Y.J. and J.Y.H. edited the manuscript. All authors read and approved the final manuscript.

Funding: This study was supported by the High Value-added Food Technology Development Program, Ministry of Agriculture, Food and Rural Affairs, Republic of Korea (317042-03-2-SB010 and 117041-03-2-SB010).

Conflicts of Interest: The authors have declared that no conflict of interests existed.

\section{References}

1. Knopman, D.S.; Petersen, R.C. Mild cognitive impairment and mild dementia: A clinical perspective. Mayo Clin. Proc. 2014, 89, 1452-1459. [CrossRef] [PubMed]

2. Andrade, C.; Radhakrishnan, R. The prevention and treatment of cognitive decline and dementia: An overview of recent research on experimental treatments. Indian J. Psychiatry 2009, 51, 12-25. [CrossRef] [PubMed]

3. Kantarci, K.; Weigand, S.D.; Przybelski, S.A.; Shiung, M.M.; Whitwell, J.L.; Negash, S.; Knopman, D.S.; Boeve, B.F.; O'Brien, P.C.; Petersen, R.C.; et al. Risk of dementia in MCI: Combined effect of cerebrovascular disease, volumetric MRI, and 1H MRS. Neurology 2009, 72, 1519-1525. [CrossRef] [PubMed]

4. Cacabelos, R. Donepezil in Alzheimer's disease: From conventional trials to pharmacogenetics. Neuropsychiatr. Dis. Treat. 2007, 3, 303-333. [PubMed]

5. Onor, M.L.; Trevisiol, M.; Aguglia, E. Rivastigmine in the treatment of Alzheimer's disease: An update. Clin. Interv. Aging 2007, 2, 17-32. [CrossRef] [PubMed]

6. van Marum, R.J. Update on the use of memantine in Alzheimer's disease. Neuropsychiatr. Dis. Treat. 2009, 5, 237-247. [CrossRef]

7. Masuda, Y. Cardiac effect of cholinesterase inhibitors used in Alzheimer's disease-from basic research to bedside. Curr. Alzheimer Res. 2004, 1, 315-321. [CrossRef]

8. Atanasov, A.G.; Waltenberger, B.; Pferschy-Wenzig, E.M.; Linder, T.; Wawrosch, C.; Uhrin, P.; Temml, V.; Wang, L.; Schwaiger, S.; Heiss, E.H.; et al. Discovery and resupply of pharmacologically active plant-derived natural products: A review. Biotechnol. Adv. 2015, 33, 1582-1614. [CrossRef]

9. Li, Z.; He, X.; Liu, F.; Wang, J.; Feng, J. A review of polysaccharides from Schisandra chinensis and Schisandra sphenanthera: Properties, functions and applications. Carbohydr. Polym. 2018, 184, 178-190. [CrossRef]

10. Giridharan, V.V.; Thandavarayan, R.A.; Sato, S.; Ko, K.M.; Konishi, T. Prevention of scopolamine-induced memory deficits by schisandrin B, an antioxidant lignan from Schisandra chinensis in mice. Free Radic. Res. 2011, 45, 950-958. [CrossRef]

11. Song, J.X.; Lin, X.; Wong, R.N.; Sze, S.C.; Tong, Y.; Shaw, P.C.; Zhang, Y.B. Protective effects of dibenzocyclooctadiene lignans from Schisandra chinensis against beta-amyloid and homocysteine neurotoxicity in PC12 cells. Phytother. Res. 2011, 25, 435-443. [CrossRef]

12. Han, Y.; Yang, H.; Li, L.; Du, X.; Sun, C. Schisanhenol improves learning and memory in scopolamine-treated mice by reducing acetylcholinesterase activity and attenuating oxidative damage through SIRT1-PGC-1alpha-Tau signaling pathway. Int. J. Neurosci. 2019, 129, 110-118. [CrossRef]

13. Hu, D.; Li, C.; Han, N.; Miao, L.; Wang, D.; Liu, Z.; Wang, H.; Yin, J. Deoxyschizandrin isolated from the fruits of Schisandra chinensis ameliorates Abeta(1)(-)(4)(2)-induced memory impairment in mice. Planta Med. 2012, 78, 1332-1336.

14. Hu, D.; Cao, Y.; He, R.; Han, N.; Liu, Z.; Miao, L.; Yin, J. Schizandrin, an antioxidant lignan from Schisandra chinensis, ameliorates Abeta1-42-induced memory impairment in mice. Oxid. Med. Cell. Longev. 2012, 2012, 721721. [CrossRef]

15. Giridharan, V.V.; Thandavarayan, R.A.; Bhilwade, H.N.; Ko, K.M.; Watanabe, K.; Konishi, T. Schisandrin B, attenuates cisplatin-induced oxidative stress, genotoxicity and neurotoxicity through modulating NF-kappaB pathway in mice. Free Radic. Res. 2012, 46, 50-60. [CrossRef]

16. Wei, B.B.; Liu, M.Y.; Chen, Z.X.; Wei, M.J. Schisandrin ameliorates cognitive impairment and attenuates Abeta deposition in APP/PS1 transgenic mice: Involvement of adjusting neurotransmitters and their metabolite changes in the brain. Acta Pharmacol. Sin. 2018, 39, 616-625. [CrossRef] 
17. Jeon, H.; Cha, D.S. Anti-aging properties of Ribes fasciculatum in Caenorhabditis elegans. Chin. J. Nat. Med. 2016, 14, 335-342.

18. Dat, N.T.; Cai, X.F.; Shen, Q.; Lee, I.S.; Kim, Y.H. New inhibitor against nuclear factor of activated T cells transcription from Ribes fasciculatum var. chinense. Chem. Pharm. Bull. 2005, 53, 114-117. [CrossRef]

19. Jung, J.W.; Kim, S.J.; Ahn, E.M.; Oh, S.R.; Lee, H.J.; Jeong, J.A.; Lee, J.Y. Ribes fasciculatum var. chinense Attenuated Allergic Inflammation In Vivo and In Vitro. Biomol. Ther. 2014, 22, 547-552.

20. Park, E.J.; Ahn, J.J.; Kweon, J.H. Effect of Hot Water Extraction Conditions on Extraction and Antioxidant Properties of Freeze-Dried Schizandra chinensis Baillon. Korean J. Food Sci. Technol. 2013, 45, 550-556. [CrossRef]

21. Ebert, U.; Kirch, W. Scopolamine model of dementia: Electroencephalogram findings and cognitive performance. Eur. J. Clin. Investig. 1998, 28, 944-949. [CrossRef]

22. Cunha, C.; Brambilla, R.; Thomas, K.L. A simple role for BDNF in learning and memory? Front. Mol. Neurosci. 2010, 3, 1. [CrossRef]

23. Cohen-Cory, S.; Kidane, A.H.; Shirkey, N.J.; Marshak, S. Brain-derived neurotrophic factor and the development of structural neuronal connectivity. Dev. Neurobiol. 2010, 70, 271-288. [CrossRef]

24. Gold, C.A.; Budson, A.E. Memory loss in Alzheimer's disease: Implications for development of therapeutics. Expert Rev. Neurother. 2008, 8, 1879-1891. [CrossRef]

25. Tarawneh, R.; Holtzman, D.M. The clinical problem of symptomatic Alzheimer disease and mild cognitive impairment. Cold Spring Harb. Perspect. Med. 2012, 2, a006148. [CrossRef]

26. Uttara, B.; Singh, A.V.; Zamboni, P.; Mahajan, R.T. Oxidative stress and neurodegenerative diseases: A review of upstream and downstream antioxidant therapeutic options. Curr. Neuropharmacol. 2009, 7, 65-74. [CrossRef]

27. Zhai, J.; Zhang, F.; Gao, S.; Chen, L.; Feng, G.; Yin, J.; Chen, W. Schisandra chinensis extract decreases chloroacetaldehyde production in rats and attenuates cyclophosphamide toxicity in liver, kidney and brain. J. Ethnopharmacol. 2018, 210, 223-231. [CrossRef]

28. Nowak, A.; Zakłos-Szyda, M.; Błasiak, J.; Nowak, A.; Zhang, Z.; Zhang, B. Potential of Schisandra chinensis (Turcz.) Baill. in Human Health and Nutrition: A Review of Current Knowledge and Therapeutic Perspectives. Nutrients 2019, 11, 333.

29. Zhang, M.; Xu, L.; Yang, H. Schisandra chinensis Fructus and Its Active Ingredients as Promising Resources for the Treatment of Neurological Diseases. Int. J. Mol. Sci. 2018, 19, 1970. [CrossRef]

30. Li, C.L.; Tsuang, Y.H.; Tsai, T.H. Neuroprotective Effect of Schisandra Chinensis on Methyl-4-Phenyl-1,2,3,6-Tetrahydropyridine-Induced Parkinsonian Syndrome in C57BL/6 Mice. Nutrients 2019, 11, 1671. [CrossRef]

31. Zhao, X.; Liu, C.; Xu, M.; Li, X.; Bi, K.; Jia, Y. Total Lignans of Schisandra chinensis Ameliorates Abeta1-42-Induced Neurodegeneration with Cognitive Impairment in Mice and Primary Mouse Neuronal Cells. PLoS ONE 2016, 11, e0152772.

32. Haider, S.; Tabassum, S.; Perveen, T. Scopolamine-induced greater alterations in neurochemical profile and increased oxidative stress demonstrated a better model of dementia: A comparative study. Brain Res. Bull. 2016, 127, 234-247. [CrossRef]

33. Umukoro, S.; Ugbomah, A.; Aderibigbe, A.; Omogbiya, A. Antioxidant Property of Jobelyn as the Possible Mechanism Underlying its Anti-amnesic Activity in Rodents. Basic Clin. Neurosci. 2013, 4, 42-49.

34. Choi, S.H.; Woodlee, M.T.; Hong, J.J.; Schallert, T. A simple modification of the water maze test to enhance daily detection of spatial memory in rats and mice. J. Neurosci. Methods 2006, 156, 182-193. [CrossRef]

35. Fayuk, D.; Yakel, J.L. Regulation of nicotinic acetylcholine receptor channel function by acetylcholinesterase inhibitors in rat hippocampal CA1 interneurons. Mol. Pharmacol. 2004, 66, 658-666. [CrossRef]

36. Ohira, K.; Hayashi, M. A new aspect of the TrkB signaling pathway in neural plasticity. Curr. Neuropharmacol. 2009, 7, 276-285. [CrossRef]

37. Song, M.; Martinowich, K.; Lee, F.S. BDNF at the synapse: Why location matters. Mol. Psychiatry 2017, 22, 1370-1375. [CrossRef]

38. Hu, B.; Nikolakopoulou, A.M.; Cohen-Cory, S. BDNF stabilizes synapses and maintains the structural complexity of optic axons in vivo. Development 2005, 132, 4285-4298. [CrossRef]

39. Sanchez, A.L.; Matthews, B.J.; Meynard, M.M.; Hu, B.; Javed, S.; Cohen Cory, S. BDNF increases synapse density in dendrites of developing tectal neurons in vivo. Development 2006, 133, 2477-2486. [CrossRef] 
40. Yan, T.; He, B.; Wan, S.; Xu, M.; Yang, H.; Xiao, F.; Bi, K.; Jia, Y. Antidepressant-like effects and cognitive enhancement of Schisandra chinensis in chronic unpredictable mild stress mice and its related mechanism. Sci. Rep. 2017, 7, 6903. [CrossRef]

41. Yan, T.; Xu, M.; Wan, S.; Wang, M.; Wu, B.; Xiao, F.; Bi, K.; Jia, Y. Schisandra chinensis produces the antidepressant-like effects in repeated corticosterone-induced mice via the BDNF/TrkB/CREB signaling pathway. Psychiatry Res. 2016, 243, 135-142. [CrossRef]

42. Ahn, K. The worldwide trend of using botanical drugs and strategies for developing global drugs. BMB Rep. 2017, 50, 111-116. [CrossRef]

43. Amin, Z.A.; Abdulla, M.A.; Ali, H.M.; Alshawsh, M.A.; Qadir, S.W. Assessment of in vitro antioxidant, antibacterial and immune activation potentials of aqueous and ethanol extracts of Phyllanthus niruri. J. Sci. Food Agric. 2012, 92, 1874-1877. [CrossRef]

44. Rush, D.K. Scopolamine amnesia of passive avoidance: A deficit of information acquisition. Behav. Neural Biol. 1988, 50, 255-274. [CrossRef]

45. Vorhees, C.V.; Williams, M.T. Morris water maze: Procedures for assessing spatial and related forms of learning and memory. Nat. Protoc. 2006, 1, 848-858. [CrossRef]

(C) 2019 by the authors. Licensee MDPI, Basel, Switzerland. This article is an open access article distributed under the terms and conditions of the Creative Commons Attribution (CC BY) license (http://creativecommons.org/licenses/by/4.0/). 